ARTICLE OPEN

Check for updates

\title{
Congenital hypothyroidism impairs spine growth of dentate granule cells by downregulation of CaMKIV
}

\author{
Qingying Tang ${ }^{1,6}$, Shuxia Chen ${ }^{1,2,6}$, Hui Wu ${ }^{1}$, Honghua Song ${ }^{3,4}$, Yongjun Wang ${ }^{4}$, Jinlong Shi ${ }^{5^{凶}}$ and Youjia Wu $^{1 凶}$
}

(c) The Author(s) 2021

Congenital hypothyroidism $(\mathrm{CH})$, a common neonatal endocrine disorder, can result in cognitive deficits if delay in diagnose and treatment. Dentate gyrus (DG) is the severely affected subregion of the hippocampus by the $\mathrm{CH}$, where the dentate granule cells (DGCs) reside in. However, how $\mathrm{CH}$ impairs the cognitive function via affecting DGCs and the underlying mechanisms are not fully elucidated. In the present study, the $\mathrm{CH}$ model of rat pups was successfully established, and the aberrant dendrite growth of the DGCs and the impaired cognitive behaviors were observed in the offspring. Transcriptome analysis of hippocampal tissues following rat $\mathrm{CH}$ successfully identified that calcium/calmodulin-dependent protein kinase IV (CaMKIV) was the prominent regulator involved in mediating deficient growth of DGC dendrites. CaMKIV was shown to be dynamically regulated in the DG subregion of the rats following drug-induced $\mathrm{CH}$. Interference of CaMKIV expression in the primary DGCs significantly reduced the spine density of dendrites, while addition of T3 to the primary DGCs isolated from $\mathrm{CH}$ pups could facilitate the spine growth of dendrites. Insights into relevant mechanisms revealed that $\mathrm{CH}$-mediated CaMKIV deficiency resulted in the significant decrease of phosphorylated CREB in DGCs, in association with the abnormality of dendrites. Our results have provided a distinct cell type in hippocampus that is affected by $\mathrm{CH}$, which would be beneficial for the treatment of $\mathrm{CH}$-induced cognitive deficiency.

Cell Death Discovery (2021)7:143; https://doi.org/10.1038/s41420-021-00530-z

\section{INTRODUCTION}

Congenital hypothyroidism $(\mathrm{CH})$ is one of important pediatric health concerns, as it impacts on child growth and neurodevelopment if delay in early treatment [1, 2]. The $\mathrm{CH}$ is resulted from defective thyroid gland development, impaired hormone biosynthesis, or several prenatal maternal factors, such as iodine deficiency and maternal IgG antibody adverse effects on fetus [3-5]. Low levels of total thyroxine (T4) and an increase of serum thyroid-stimulating hormone (TSH) in hypothyroidism resulted in deficiency of biologically active triiodothyronine (T3) in fetus [5-8]. Extensive studies have described that reduction of T3 level exerts profound effects on structural and functional changes within brain, depending on developmental stages [9-11]. T3 deficiency is known to reduce proliferation, survival, and differentiation of neuronal and glial progenitors [12, 13]. In the adult brain, however, T3 perturbation causes depressive behavior and deteriorates cognitive function [11, 14, 15]. It is well established that hippocampus is one of primarily affected brain regions of $\mathrm{T} 3$, where a reduction of the thyroid hormone will result in the impairment of neurogenesis, as well as cognitive and behavioral deficits $[14,16]$. Although T3-mediated signaling through nuclear receptors $\mathrm{TH}$ receptor alpha and beta has been well documented in link with the structural abnormality of hippocampus, such as the downstream Emx2 and Klf9 governing neurogenesis [17, 18], the effects of hypothyroidism on the development of hippocampus and the underlying mechanisms are not fully elucidated.

Dentate gyrus (DG), a subregion of the hippocampus is involved in the memory formation. The developmentally generated and adult-generated dentate granule cells (DGCs) are continuously added to the DG and integrated into hippocampal memory networks $[19,20]$. DGCs extend axons along the mossy fiber tract to CA3 and receive excitatory synaptic input from perforant path afferents [21-23]. The proper formation and morphogenesis of DGC dendrites is essential to the establishment of neuronal connectivity [24]. Deficits in dendrite size and complexity have been shown to be associated with the impaired cognitive function or other neurological disorders, such as epilepsy $[25,26]$. Previous study has demonstrated that iodine deficiency delays the maturation of newborn granule neurons in DG [27], it is reasonably assumed that $\mathrm{CH}$ is able to affect the growth of DGC dendrites, in addition to the proliferation and survival of progenitors.

Calcium/calmodulin-dependent protein kinase IV (CaMKIV) has been shown to regulate the dendrite growth of both cortical and hippocampal neurons via CREB and CREB-binding protein (CBP)-

\footnotetext{
${ }^{1}$ Department of Pediatrics, Affiliated Hospital of Nantong University, Nantong, Jiangsu Province, China. ${ }^{2}$ Department of Pediatrics, The Fourth Affiliated Hospital of Nantong University, Yancheng, Jiangsu Province, China. ${ }^{3}$ Center of Special Inspection, Affiliated Hospital of Nantong University, Nantong, Jiangsu Province, China. ${ }^{4}$ Key Laboratory of Neuroregeneration of Jiangsu and Ministry of Education, Co-innovation Center of Neuroregeneration, Nantong University, Nantong, Jiangsu Province, China. ${ }^{5}$ Department of Neurosurgery, Affiliated Hospital of Nantong University, Nantong, Jiangsu Province, China. ${ }^{6}$ These authors contributed equally: Qingying Tang, Shuxia Chen. Edited by: Ivano

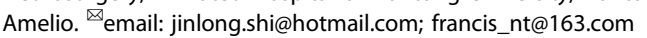

Received: 9 March 2021 Accepted: 23 May 2021

Published online: 14 June 2021 
regulated transcription [28-31]. An early study has demonstrated that the promoter of CaMKIV contains T3 response element, and CaMKIV can be regulated directly by $\mathrm{T} 3$ in primary cultured neurons from fetal cortex $[32,33]$. These imply that $\mathrm{CH}$ may affect the dendrite growth of DGCs through regulation of CaMKIV, and eventually contributes to impairment of cognitive function. In the present study, we successfully established $\mathrm{CH}$ model of rat fetus and investigated the $\mathrm{CH}$ effects on the cognitive function of the animals. We further observed the numbers and dendrite growth of DGCs in $\mathrm{CH}$ pups. Subsequent transcriptome profile analysis revealed that CaMKIV acted as a central hub responsible for $\mathrm{CH}$ mediated impairment of DGC dendrite growth during development of hippocampus. Our results have provided new mechanism of $\mathrm{CH}$-mediated deficiency of hippocampal memory circuits.

\section{RESULTS}

Continuous treatment of MMI on dams results in $\mathrm{CH}$-mediated cognitive deficits of offspring

Whether maternal thyroid hormones are necessary for normal embryonic development is uncertain until T4 and T3 are detected in the embryonic tissues of rat and human before onset of fetal thyroid function [34]. 2-Mercapto-1-methylimidazole (MMI) has been extensively applied to induce maternal and fetal hypothyroidism $[35,36]$. So, it was given in drinking water of rat dams from day 9 of gestation till postnatal day 21 (P21). To assess MMIinduced $\mathrm{CH}$ efficiency in fetal rats, the TSH and T4 levels in serum of both dams and pups were thereafter determined. Results showed that TSH contents in dams at day 18 of gestation and the P1, P7, and P21 pups significantly increased following MMI treatment, while T4 levels markedly reduced comparing to the normal groups (Fig. 1A-D). These changes of TSH and T4 levels in serum were in consistent with the clinicopathologic indicators of hypothyroidism. Further phenotype observation displayed that the body weights of $\mathrm{CH}$ pups were much lower than those of controls from P7 onward (Fig. 1E-H). Morris water maze test was then performed to evaluate the effects of maternal $\mathrm{CH}$ on learning and cognitive function of the offspring at 24 weeks. The escape latencies and swimming distances from $\mathrm{CH}$ group were significantly longer than those of control from day 2 to day 4 (Fig. 1l, J). Probe trial test on fifth day for recording the number of times each rat crossing the platform area and the duration time in island, showed that the $\mathrm{CH}$ offspring suffered from severe behavioral deficits. Also, the escape latencies at day 5 were significantly longer than those of the control (Fig. 1K-M). The data indicate that $\mathrm{CH}$ severely impairs the cognitive function of the rats.

\section{CH leads to aberrant growth of DGC dendrites in pup hippocampus}

As integration of new neurons into DG and their maturation are essential for supporting memory networks in hippocampus $[20,37]$, the number of neurons in DG subregion and the morphology of DGC dendrites in $\mathrm{CH}$ pups at different stages were thus observed. Results showed that $\mathrm{CH}$ did not affect the number of neurons in the DG of pups, as defined by Nissl staining (Fig. 2A, $B, G)$. However, MMI treatment significantly decreased the density of dendritic spines observed by Golgi staining (Fig. $2 \mathrm{C}-\mathrm{F}, \mathrm{H}$ ). The results indicate that $\mathrm{CH}$-mediated cognitive deficits of rat might be involved in the aberrant spine growth of DGC dendrites in pups.

\section{Molecular aspects of $\mathrm{CH}$ action on developing hippocampus of} rat

Thyroid hormone, primarily T3, has important effects on the development of rat hippocampus by influence on gene expression in a manner of genomic or nongenomic actions $[18,38]$. To reveal the molecular aspects of $\mathrm{CH}$ action on the developing hippocampus of rat, which might provide clues involved in abnormality of DGC dendrites, we performed transcriptome analysis of hippocampal tissues dissected from $\mathrm{CH}$ pups at P1, P7, and P21, respectively. A total of 388, 147, and 385 differentially expressed genes (DEGs) were identified at the three time points, with defined criteria of $P<0.05$ and a greater or less than twofold changes (Fig. 3A, C, E and Table S1). The Gene Ontology (GO) enrichment analysis classified these DEGs involved in the biological process of anatomical structure morphogenesis, negative regulation of growth, developmental process, and response to hormone (Fig. 3B, D, F). We further integrated the DEGs at three time points, and characterized nine functional genes associated with important biological processes, including neuroactive ligand-receptor interaction following $\mathrm{CH}$ (Fig. 4A, B). These genes displayed dynamic alteration in the hippocampus comparing to the control, as shown by heatmap and cluster dendrogram (Fig. 4C). To elucidate the mechanism of $\mathrm{CH}$ impairment on dendritic growth of hippocampal neurons, we performed ingenuity pathway analysis (IPA) for the DEGs integrated at P1, P7, and P21. A gene network was constructed, and as a result identifying that CaMKIV was highlighted as the prominent regulator in response to reduction of thyroid hormone (Fig. 4D). The data indicate that CaMKIV is a potential player in mediating aberrant spine growth of DGC dendrites in the $\mathrm{CH}$ offspring.

\section{CaMKIV is downregulated in the granule cell layer of dentate gyrus following $\mathrm{CH}$ of pups}

To substantiate the inference drawn from transcriptome analysis, both RT-PCR and western blot were performed to examine the expression changes of CaMKIV at transcriptional and translational levels in the hippocampus, following $\mathrm{CH}$ of pups. Consistently, expression of CaMKIV in $\mathrm{CH}$ neonatal rat was significantly downregulated at P1, P7, and P21, comparing with those in normal group (Fig. 5A-C). Immunofluorescence demonstrated that CaMKIV protein distributed in the DG, $C A 1$, and $C A 3$ regions of hippocampus, with the positive signals markedly reduced in the granule cell layer of DG following $\mathrm{CH}$ (Fig. 5D). The data indicate that $\mathrm{CH}$ negatively regulates the expression of CaMKIV in the hippocampal DGCs of pups.

\section{Knockdown of CaMKIV in DGCs is associated with decrease of spine density}

To elucidate the potential physiological function of CaMKIV reduction in the DGCs, we cultured the primary DGCs, followed by interference of the CaMKIV expression using the siRNA oligonucleotides. The siRNA2 with nearly $60 \%$ knockdown efficiency was selected for the subsequent experiments (Fig. 6A, B). Transfection of CaMKIV siRNA2 to the DGCs for $24 \mathrm{~h}$ resulted in the decrease of spine density in comparison with the control (Fig. 6D-H). Also, it led to the deficient expression of creb (Fig. 6C). These results indicate that $\mathrm{CH}$-mediated downregulation of CaMKIV in the DGCs are implicated in the deficient spine growth of dendrites.

\section{T3 is able to potentiate spine growth of DGCs from $\mathrm{CH}$ pups through regulation of CaMKIV/CREB signaling}

Given that $\mathrm{CH}$ was able to induce spine deficiency of DGCs in vivo, we thus attempted to reverse these harmful effects of $\mathrm{CH}$ on the DGCs by the treatment with thyroid hormone T3 in vitro. Addition of $5 \mathrm{nM}$ T3 to the culture medium of primary DGCs from CH P3 pups for $24 \mathrm{~h}$ was able to significantly increase the density of spines (Fig. 7A, B). CREB can be directly phosphorylated by CaMKIV and ERK to activate multiple genes essential for neurogenesis, neuronal survival, and plasticity in hippocampus [39]. To examine whether the CaMKIV/CREB signal pathway was involved in the T3mediated spine growth, the protein level of phosphorylated CREB was thus determined. Results showed that T3 could markedly activate both CaMKIV and CREB kinases, but made no effects on the activation of ERK (Fig. 7C-H). Knockdown of CaMKIV accordingly resulted in the decease of phosphorylated CREB, rather than ERK (Fig. 7I-N). The data indicate that endogenous T3 
A
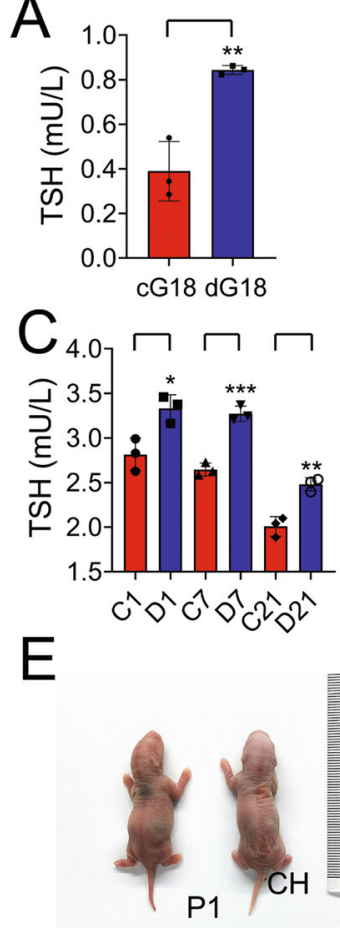

G

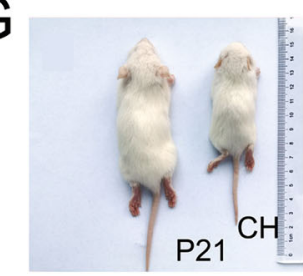

B
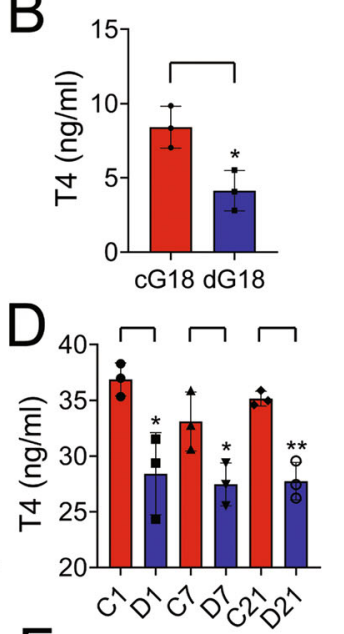

$\mathrm{F}$

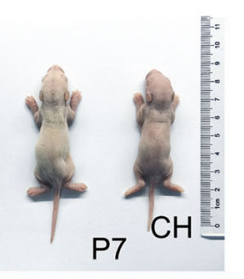

$\mathrm{H}$

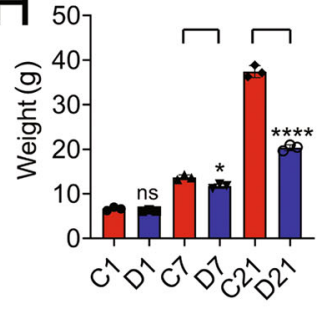

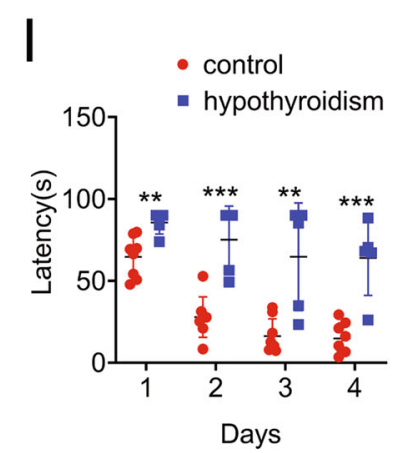

K

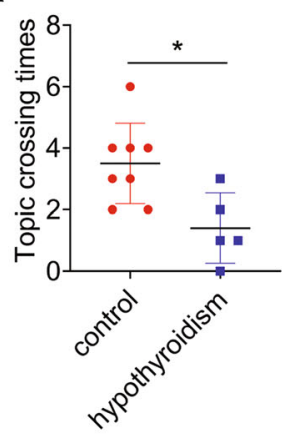

$\mathrm{J}$

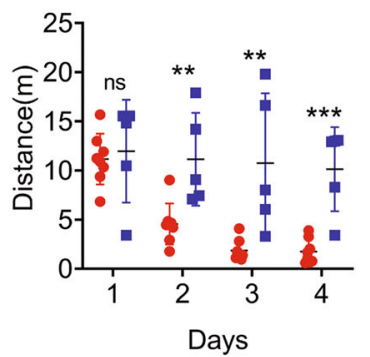

$\mathrm{L}$

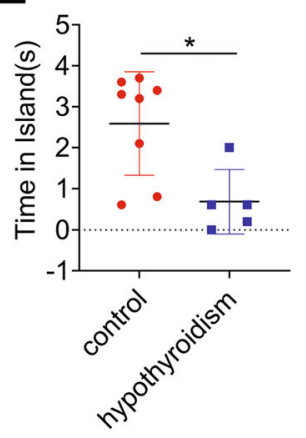

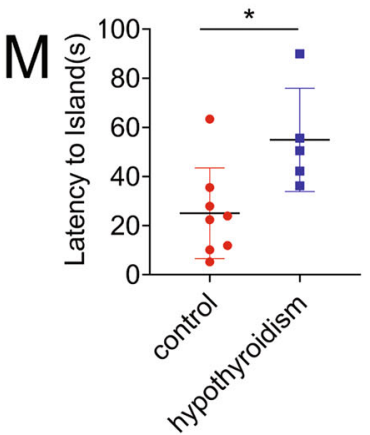

Fig. 1 MMI treatment resulted in $\mathbf{C H}$ and cognitive deficits of rat offspring. A, B Measurement of TSH (A) and T4 (B) in serum of dams at day 18 of gestation following given $0.02 \% \mathrm{MMI}$ in the drinking water from the day 9 of gestation. $n=3$. C, D Measurement of TSH (C) and T4 (D) in serum of P1, P7, and P21 pups. $n=12$. Experiments were performed in triplicates. E-H Body weight determination of P1, P7, and P21 pups following $\mathrm{CH} . \mathrm{C} 1 / 7 / 21$ indicates control, and D1/7/21 indicates $\mathrm{CH} . n=12$. Experiments were performed in triplicates. I Morris water maze tests of rat offspring at 24 weeks following $\mathrm{CH}$ showed escape latency in the acquisition phase. J Swimming distance in the target quadrant in the acquisition phase. $\mathbf{K}$ Number of target crossings in the probing trial. $\mathbf{L}$ Times staying in platform in the probing trial. $\mathbf{M}$ Escape latency in the probing trial. $n=5$. Error bars represent the standard deviation $(* P<0.05)$.

is able to rescue the spine density of DGC dendrites in $\mathrm{CH}$ pups through regulating CaMKIV/CREB signaling.

\section{$\mathrm{CH}$ leads to the aberrant activation of CREB in the hippocampus of pups}

CaMKIV has been found to mediate an early transient phase of CREB phosphorylation, while ERK/MAPK signaling cascade is responsible for a persistent phase of phosphorylation [40]. To understand the regulatory relationship between CaMKIV and CREB proteins in the hippocampus of $\mathrm{CH}$ pups, the phosphorylation of CREB in the hippocampal tissues of pups was thus examined at P1, P7, and P21, following dams treatment with MMI. The protein levels of phosphorylated CREB were unexpectedly inconsistent with those of CaMKIV, but in parallel with those of ERK signaling (Fig. $8 \mathrm{~A}-\mathrm{C}$ ). Immunostaining demonstrated that CREB was distributed in the multiple neuronal types of hippocampal subregions, in addition to localization in the DGCs (Fig. 8D). The results indicate that $\mathrm{CH}$-induced deficiency of CaMKIV primarily affects spine aberrancy of DGCs by inactivation of CREB in a transient and region-specific manner.

\section{DISCUSSION}

$\mathrm{CH}$ is the most common neonatal endocrine disorder, with the incidence between 1:2000 and 1:4000 births [41]. $\mathrm{CH}$ is caused by thyroid dysgenesis (primary $\mathrm{CH}$ ) or impaired TSH-mediated stimulation of the thyroid gland (central $\mathrm{CH}$ ) [1, 42]. However, maternal hypothyroxinemia can also bring in fetal thyroid hormone deficiency during the embryo development [43-45]. A plethora of evidence suggests that thyroid hormone is essential for normal development, growth, and metabolic regulation of the organs, especially for the neurogenesis and differentiation in CNS $[46,47]$. Screening of $\mathrm{CH}$ is routinely based on elevated levels of TSH and/or decreased concentrations T4 in serum of infants [8]. In the present study, we established $\mathrm{CH}$ model of rat pups by constantly supplying $\mathrm{MMI}$ in the drinking water of dams from day 9 of gestation. Measurement of TSH and T4 concentration in the serum of pups confirmed a successful preparation of the $\mathrm{CH}$ offspring, by which the impaired cognitive function was objectively evaluated. Several earlier studies have mentioned that thyroid hormones are not required for normal embryonic development before onset of fetal thyroid function. 


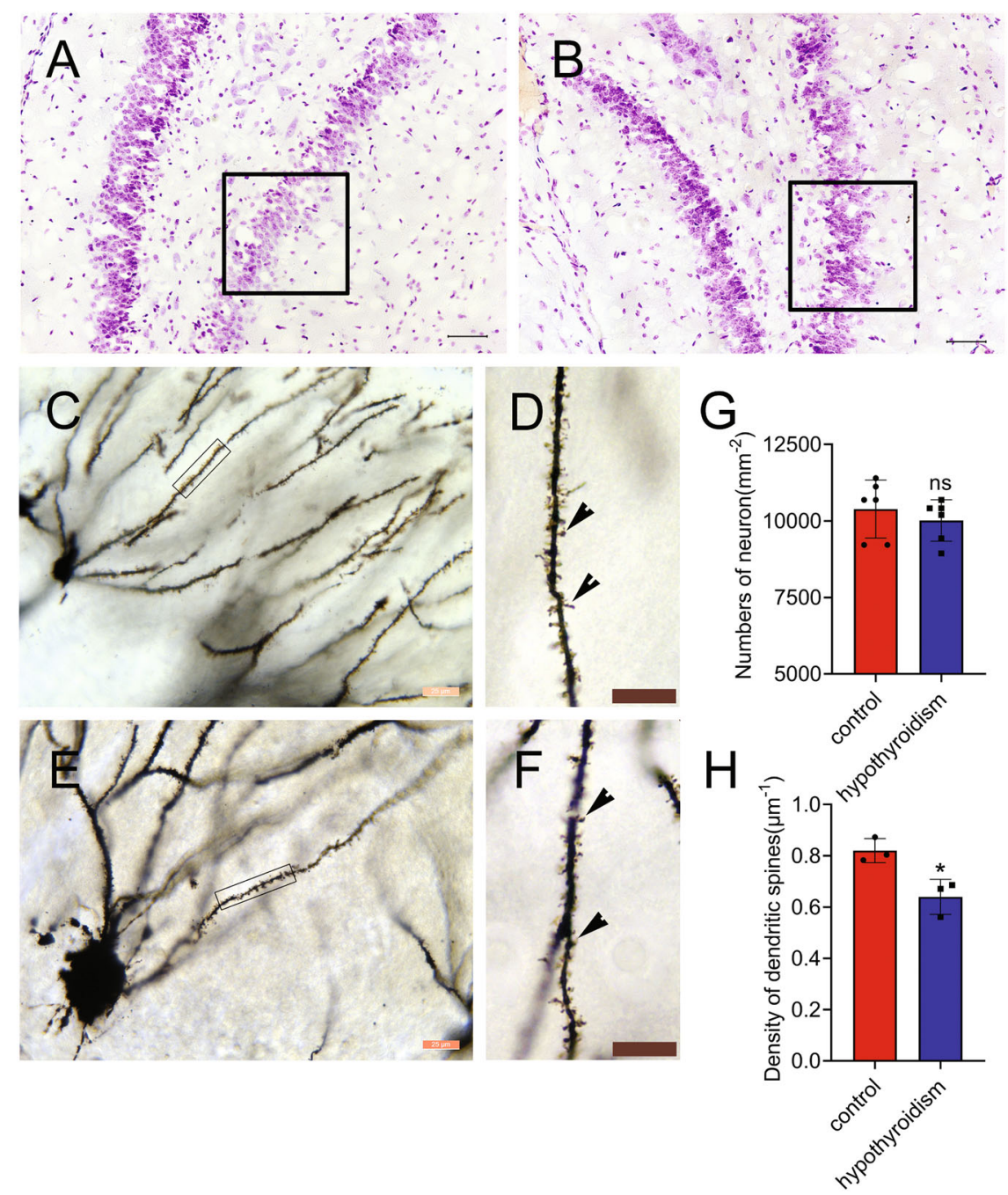

Fig. 2 Effects of CH on the spine density of DGCs in the DG subregion of rat pups. A, B Nissl's staining of P21 pup hippocampus with or without $\mathrm{CH}$. C-H Comparison of dendritic spine density of DGCs by Golgi staining between P21 pups with or without CH. The rectangles in $\mathbf{A}$ and $\mathbf{B}$ indicate detection sites of dendritic spines in DG subregion. The rectangles in $\mathbf{C}$ and $\mathbf{E}$ indicate region magnified in $\mathbf{D}$ and $\mathbf{F}$. $\mathbf{H}, \mathbf{G}$ Statistical analysis of C, E and A, B, respectively. Arrowheads indicate spines. Statistic analysis of spine density in triplicates each 15 fields. Scale bars, $50 \mu \mathrm{m}$ in $\mathbf{A}, \mathbf{B} ; 25 \mu \mathrm{m}$ in $\mathbf{C}, \mathbf{E} ; 10 \mu \mathrm{m}$ in $\mathbf{D}, \mathbf{F}$. Error bars represent the standard deviation $\left({ }^{*} P<0.05\right)$.

We are herein in favor of the views that maternal hypothyroxinemia is correlated with developmental disorders of neurological system [48].

DGCs are bipolar neurons with dendrite extending into the molecular layer and axon entering the hilar region of hippocampus. The dendrites receive afferent input from fibers of the lateral and medial entorhinal cortex in the outer molecular layer, and from commissural/associational fibers in the inner molecular layer $[49,50]$. So, the normal morphology of the DGCs dendrites is developmentally essential for the cognitive function of the offspring, because they connect with both cortical and hippocampal internal input [51]. In fact, the aberrant DGC dendrites have been found to impair long-term spatial memory, temporal order memory, and result in seizure activity by forming an abnormal excitatory feedback circuit $[52,53]$. Although granule cells are relatively resistant to a variety of neurological insults [54], several evidences have shown that they are selectively vulnerable to the reduction of circulating hormones, such as adrenal hormones $[55,56]$. As such, it is not surprising that $\mathrm{CH}$ of pups results in abnormal development of DGC dendrites, which in turn affects cognitive function of the offspring.
Members of the CaMK family are classified into two classes based on their function, the multifunctional CaMKs that each has several substrates (CaMKK, CaMKI, CaMKII, and CaMKIV) and the substrate-specific CaMKIII [57]. Among these members, CaMKII and CaMKIV have extensively been shown to play critical roles in the regulation of neuronal plasticity and cognitive functions $[30,58]$. As for CaMKII, its expression level exceeds $1 \%$ of total protein in hippocampus and neocortex [58], but it seems less sensitive to the absence of thyroid hormones in comparison with CaMKIV [59]. The protein of CaMKIV is observed to be highly expressed in the cerebral cortex, cerebellum, and hippocampus. Its deficiency exerts a severe influence on the brain development $[30,60,61]$. The primary action of CaMKIV on cortical neurons attributes to mediating dendrite complexity via the regulation of specific morphological features of the dendrite arbor [29, 30]. In the present study, we demonstrated that $\mathrm{CH}$-induced deficiency of CaMKIV significantly reduced the spine density of DGCs, suggesting the conservative function of CaMKIV in regulating dendrite growth of multiple types of neurons.

As a prototypical stimulus-inducible transcription factor, CREB within neurons is responsive to different physiological stimuli. 

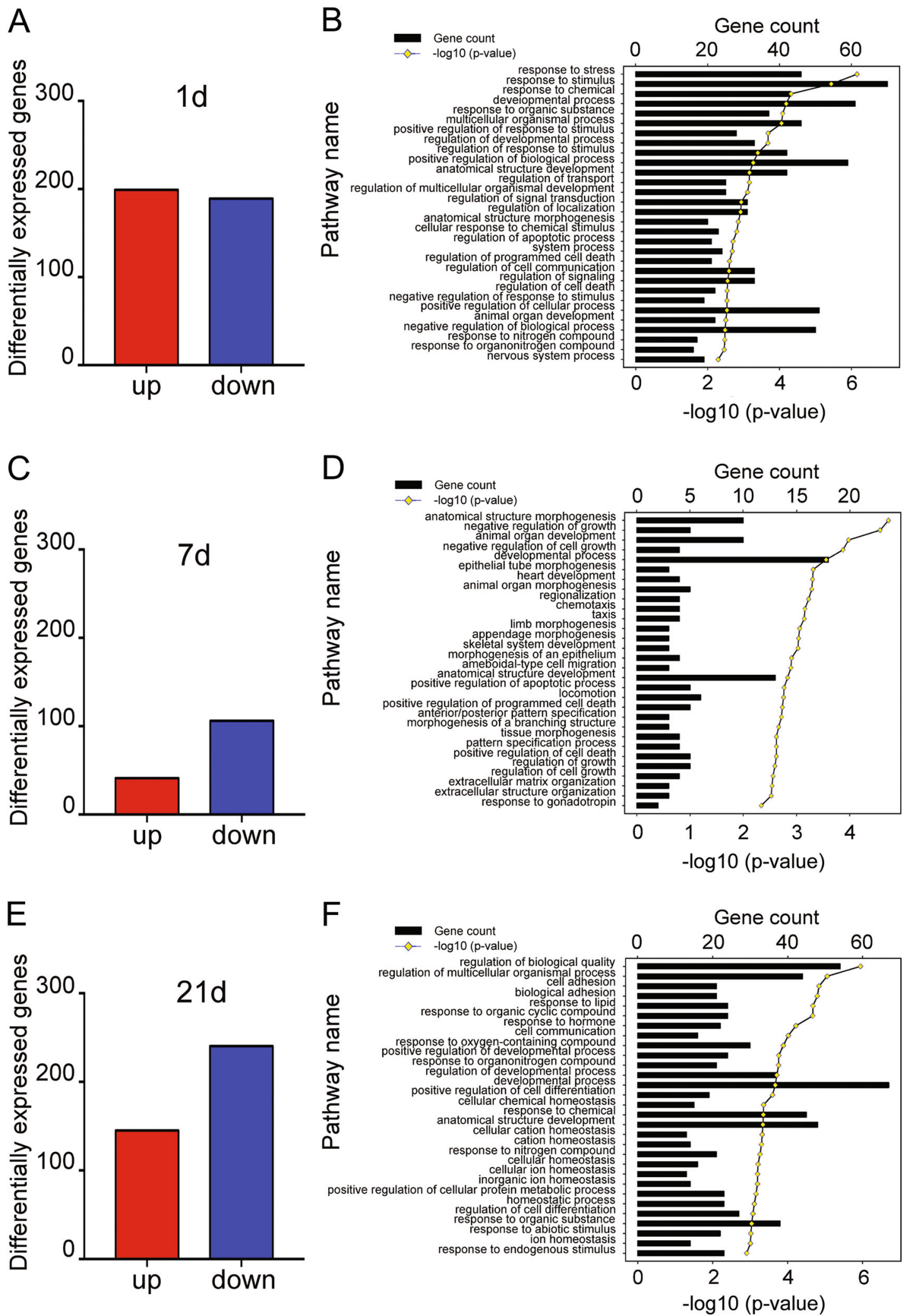

Fig. 3 Functional annotations of DEGs in the pup hippocampus following CH. A, C, E Bar graphs of DEGs in the P1, P7, and P21 rat pup hippocampus following $\mathrm{CH}$. B, D, F Most significantly enriched groups for the DEGs relating to biological process by GO annotations. The significance of enrichment is expressed as a $-\log 10(P$ value). 

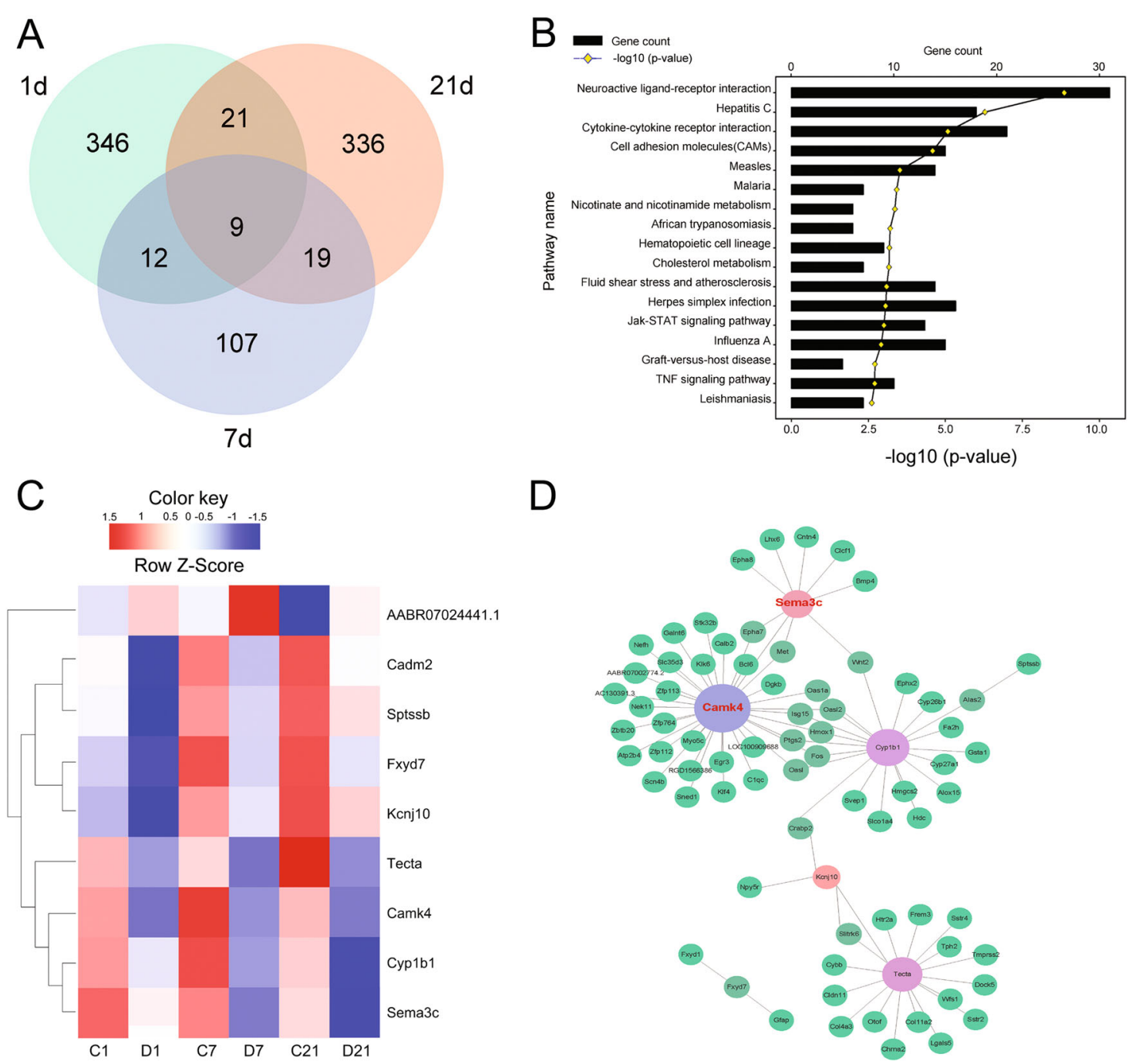

D

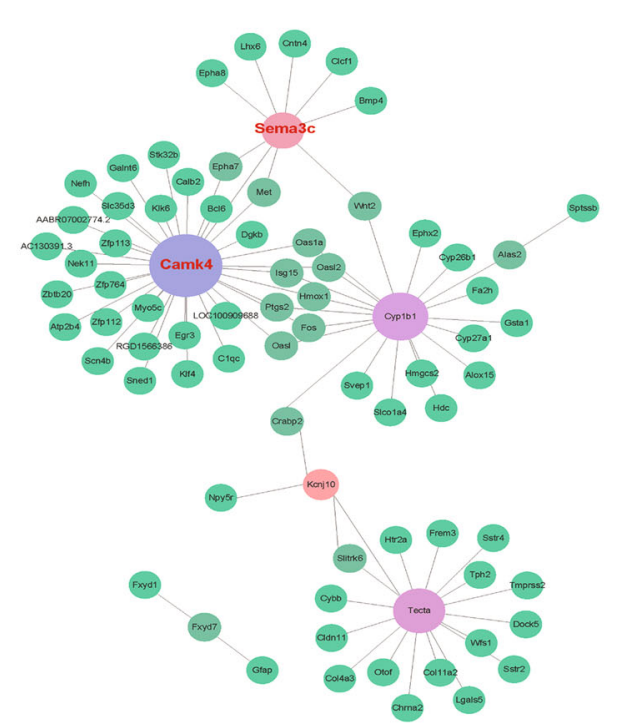

Fig. 4 Analysis of key player in mediating aberrant spine growth of DGC in the CH offspring of rat. A Integration of DEGs in the hippocampus of P1, P7, and P21 rat pups following $\mathrm{CH}$. B Most significantly enriched groups for the integrated DEGs relating to pathways. C Heatmap and cluster dendrogram of integrated DEGs in the hippocampus of P1, P7, and P21 rat pups following CH. D A reconstructed gene network was created using the ingenuity pathway analysis software (IPA) on the basis of integrated DEGs.

Activation of CREB immediately initiates gene transcription, contributing to proliferation of neuronal precursors, as well as the survival, synaptic connectivity of developing neurons, and the learning and memory of the adult animals [62-65]. The Ser133 in KID domain of CREB is phosphorylated by activators, making CBP bind to facilitate neuronal activity-related gene expression, such as c-fos, egr 1 , and egr3 $[66,67]$. CREB has been detected in multiple regions of the brain at various developmental stages [65]. A number of kinases, including CaMKIV, PKA, AKT, and ERK, are associated with the phosphorylation of CREB with distinct phases of activation [68, 69]. For example, CaMKIV mediates a transient, whereas ERK mediates a sustained phosphorylation of CREB [70]. In the present study, interference of CaMKIV in the DGCs could result in changes of CREB phosphorylation at $30 \mathrm{~min}$, suggesting a transient regulatory function of the kinase. Interestingly, $\mathrm{CH}$ mediated CaMKIV deficiency failed to reduce protein levels of phosphorylated CREB at hippocampus of pups at P1, P7, and P21. The reason is probably attributed to the action of multiple factors on the CREB, as several hormones, neurotransmitters, growth factors, and neurotrophins are able to facilitate CREB phosphorylation during the development of hippocampus [65]. However, the conclusion needs to be further clarified.
In conclusion, $\mathrm{CH}$ decreased the expression of CaMKIV kinase in the DGCs of the rat pups, which resulted in the reduced spine density of DGCs dendrites, and as a result, the cognitive impairment of the offspring.

\section{MATERIALS AND METHODS}

\section{Animals}

Adult female Sprague-Dawley (SD) rats, weighing 180-220 g, were provided by the Center of Experimental Animals, Nantong University. All animal experiments were approved by the Animal Care and Use Committee of Nantong University and the Animal Care Ethics Committee of Jiangsu Province. All rats were housed in standard cages (five rats in each cage) in an environment maintained at $22 \pm 2{ }^{\circ} \mathrm{C}$ on a $12-12 \mathrm{~h}$ light-dark cycle, and had free access to water and food.

\section{Establishment of $\mathrm{CH}$ model of rat pups}

To induce $\mathrm{CH}$ of rat pups, the pregnant dams were given $0.02 \% \mathrm{MMI}$ in the drinking water from embryonic day 9 (E9, the day of appearance of the vaginal plug was E0) until P21 of the pups. The dams of the control group were given clean drinking water. The concentration of TSH and T4 in the serum of $\mathrm{P} 1, \mathrm{P} 7$, and $\mathrm{P} 21$ pups and dams at day 18 of gestation was measured to verify a successful preparation of the $\mathrm{CH}$ model. 
A

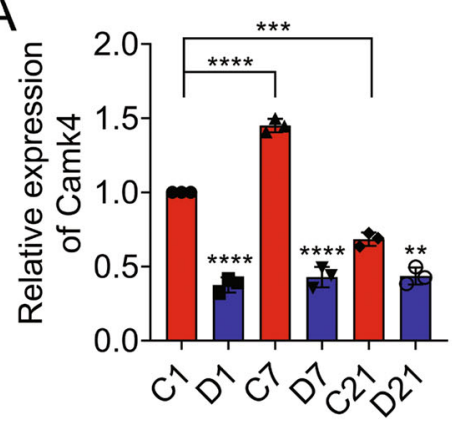

Days of age

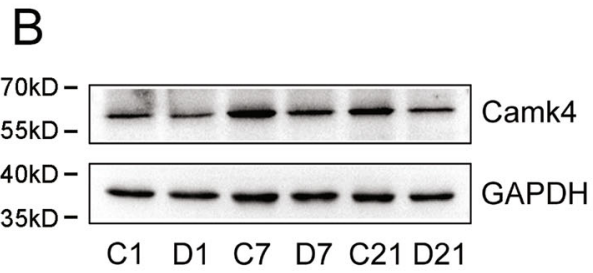

C

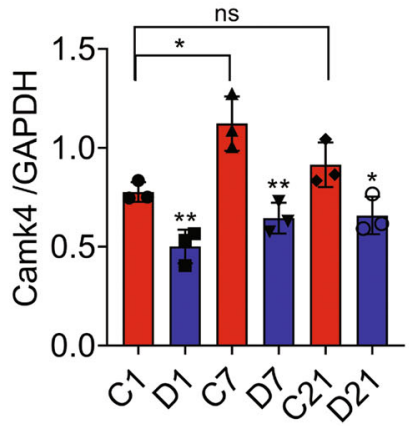

Days of age
D
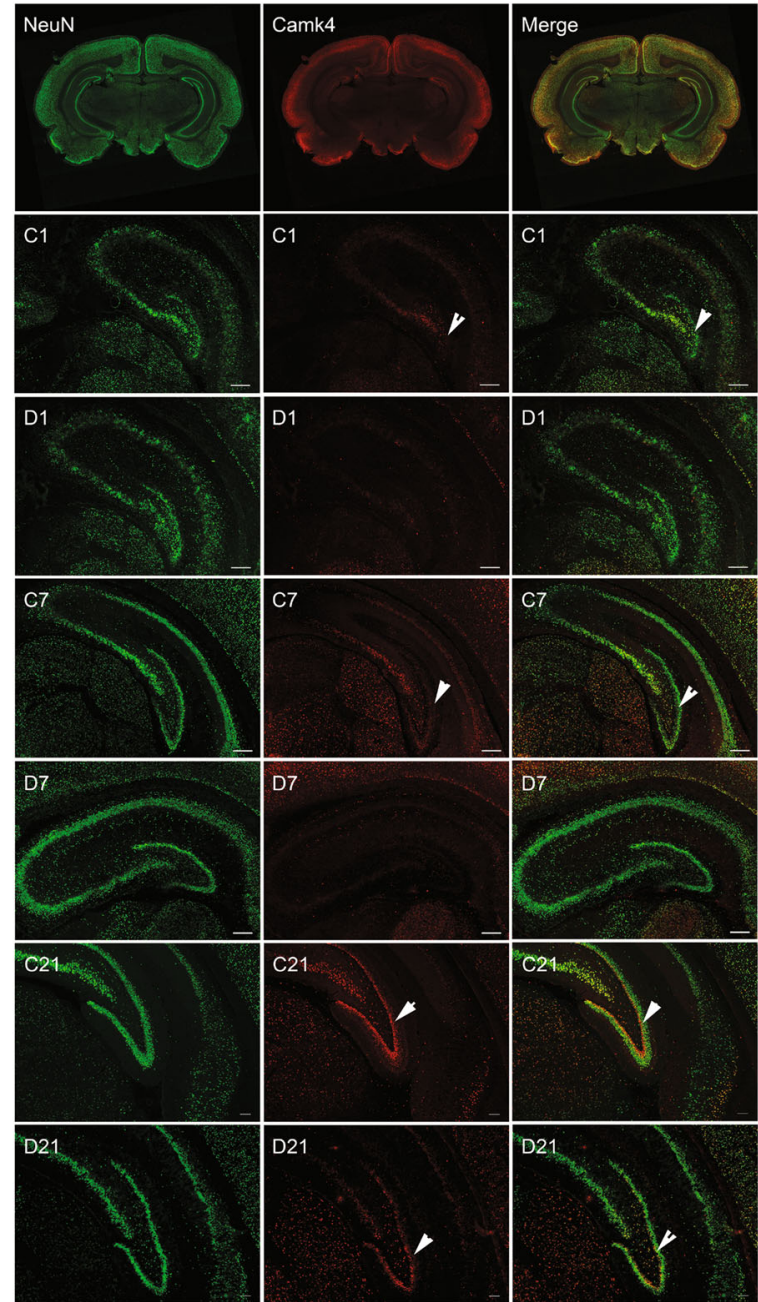

Fig. 5 Dynamic expression of CaMKIV in the hippocampus of rat pups following CH. A RT-PCR analysis of CaMKIV transcription in the hippocampus of P1, P7, and P21 pups following CH. B Western blot analysis of CaMKIV. C Statistical analysis of B. Experiments were performed in triplicates. Error bars represent the standard deviation $(P<0.05)$. D CaMKIV immunostaining of the cross section from hippocampus of $\mathrm{P} 1$, $\mathrm{P} 7$, and P21 pups following $\mathrm{CH}$. C1/7/21 indicates control, and D1/7/21 indicates $\mathrm{CH}$. Arrowheads indicate positive signals in the dentate gyrus. Scale bars, $200 \mu \mathrm{m}$.

\section{Determination of TSH and T4 concentrations}

All blood samples, including dams and pups at P1, P7, and P21, were collected and centrifuged at 3000 r.p.m. for $20 \mathrm{~min}$. The upper serum was extracted and processed for TSH and T4 determination, according to the protocol provided by the manufacturer (Enzyme-linked Biotechnology, China). Briefly, $50 \mu \mathrm{l}$ of standard or sample was added to the appropriate wells, followed by addition of $100 \mu$ l of enzyme conjugate. After incubation at $37^{\circ} \mathrm{C}$ for $60 \mathrm{~min}$, the incubation mixture was removed and fill each well completely with wash solution (1x). The procedure was repeated for four times, and the plate was inverted for natural dry until no appearance of moisture. Then, $50 \mu \mathrm{l}$ of substrate $A$ and $50 \mu$ l of substrate B were added to each well. After gently mixture, they were allowed to incubate at $37^{\circ} \mathrm{C}$ for 15 min avoiding of light. Finally, $50 \mu$ l of stop solution was added, and the optical density was read at $450 \mathrm{~nm}$ using a microtiter plate reader within $15 \mathrm{~min}$.

\section{Morris water maze tests}

The Morris water maze test was used to measure the learning and memory abilities of the offspring. After establishment of the $\mathrm{CH}$ model at 24 weeks, the rats were trained for 4 days each four times. In the place navigation test, the rats were put into the water facing the pool wall (back to platform) with an entry point, to observe and record the time, and distance needed to find and climb onto the platform (escape latency and distance). If the rats did not find the platform within $90 \mathrm{~s}$, they were guided to the platform, and the escape latency was recorded as $90 \mathrm{~s}$. The escape latencies of rats were recorded on days $1-4$. In the spatial probe test, the platform was removed on day 5, and the times of crossing the original platform location in the pool, duration, and latency within $90 \mathrm{~s}$ were recorded. Data collection and processing were performed using a Morris water maze image automatic monitoring system.

\section{Golgi staining}

Golgi staining was performed according to the instruction of Hito Golgi staining kit (HTKNS1125NH). Briefly, the dissected hippocampus from P21 pup was impregnated at room temperature for 2 weeks in a mixture of solution $A$ and solution $B$, then immersed in solution $C$ at $4{ }^{\circ} \mathrm{C}$ for $48 \mathrm{~h}$. The hippocampus was sectioned into $100-\mu \mathrm{m}$ slices and transferred onto $2 \%$ gelatin-coated slides. The slices were dried at room temperature for 2 days and then stained with a mixture of solution $D$, solution $E$, and distilled water (1:1:3 ratio) for $10 \mathrm{~min}$, followed by dehydration with gradient ethanol. The samples were subsequently cleared by xylene and mounted with Permount Medium (Fisher Scientific, Pittsburgh, PA). Sections were observed under the microscope, and the morphology of the dendrites was photographed.

\section{Nissl's staining}

The freshly dissected hippocampus of P21 pup was sectioned at $12 \mu \mathrm{m}$. The slices were dried at room temperature for $30 \mathrm{~min}$, followed by immersing with distilled water. The slices were stained in cresyl violet solution for $30 \mathrm{~min}$, and then were dehydrated with gradient alcohol. After clearing with xylene, they were mounted with undiluted xylene based resinous mounting medium and observed under microscope. 


\section{A}
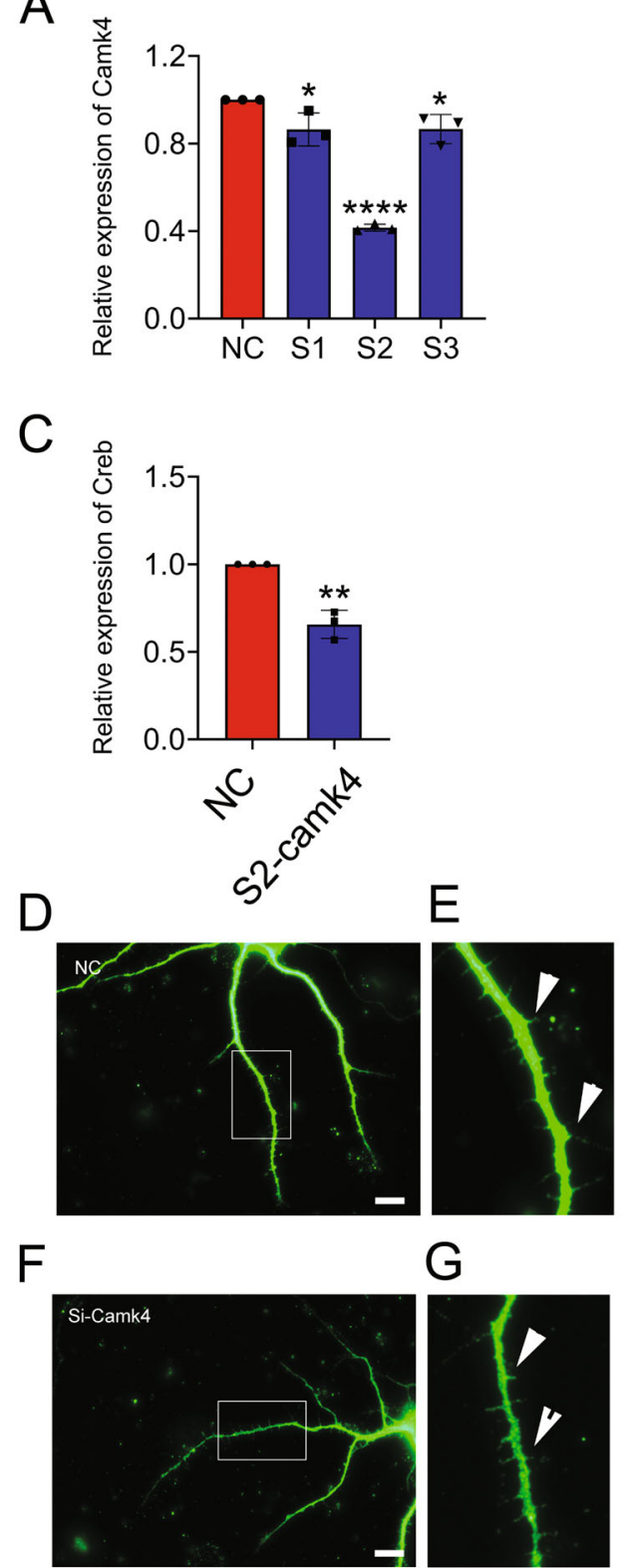

G

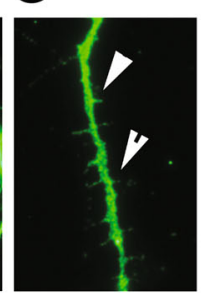

B
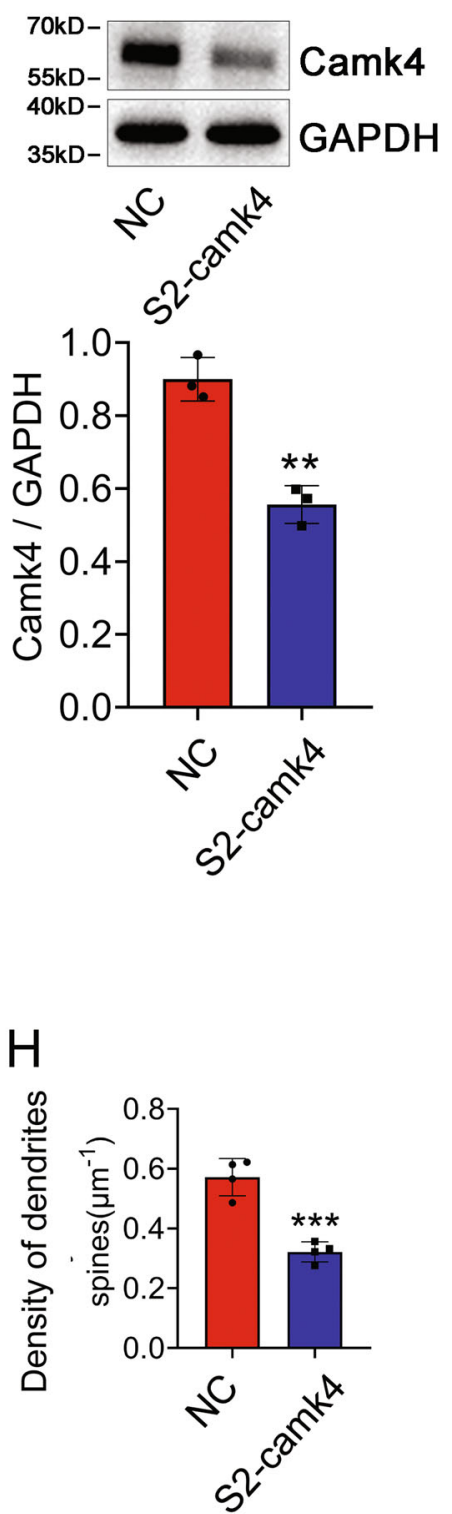

Fig. 6 Effects of CaMKIV deficiency on the spine density of DGC dendrites. A, B Interference efficiency of three siRNA oligonucleotides for CaMKIV was measured by RT-PCR (A) and western blot (B). The siRNA2 was used for the knockdown experiments. C Transcriptional analysis of CREB following CaMKIV knockdown of DGCs for $24 \mathrm{~h}$. D-G Detection of the spine density of dendrites stained by MAP2 antibody following CaMKIV knockdown of primary DGCs and kept for culture of another 5 days. Scramble was used as control. The rectangle indicates region magnified. H Statistic analysis of spine density in quadruplicates each 15 fields. Six pups of each group were used to isolate DGCs. Arrowheads indicate spines. Scale bars, $10 \mu \mathrm{m}$.

\section{Primary culture of dentate granule cells and siRNA transfection}

Cultures of dissociated granule cells were prepared from P3 to P4 SD rats, as previously described [71]. Briefly, the DG were dissociated in ice-cold Gey's balanced salt solution in the presence of D-glucose $(6.50 \mathrm{~g} / \mathrm{l})$, followed by digestion with $0.125 \%$ trypsin and $0.01 \%$ DNase I at $37^{\circ} \mathrm{C}$ for $20 \mathrm{~min}$. The horse serum was then added to stop the digestion, and the cells were suffered to centrifuge at 1000 r.p.m. for $4 \mathrm{~min}$. After removing the supernatants, the cells were dispersed in $2 \mathrm{ml}$ of culture medium with arabinofuranosyl cytidine and serum at $37^{\circ} \mathrm{C}$. For primary cultures, the dissociated granule cells were plated onto $13-\mathrm{mm}$ cover slips coated with poly-D-lysine at a cell density of $1 \times 10^{4} \mathrm{cells} / \mathrm{cm}^{2}$ in culture medium in 24 -well plates, and incubated at $37^{\circ} \mathrm{C}$ in a humidified $5 \% \mathrm{CO}_{2}$ and $95 \%$ air atmosphere.

For siRNA transfection of the DGCs, it is achieved by the protocol of the manufacturer (RiboBio, China). Briefly, $120 \mu \mathrm{l}$ of $1 \times$ riboFECT $^{\text {m }} \mathrm{CP}$ buffer was added to $15 \mu \mathrm{l}$ of $20 \mu \mathrm{M}$ siRNA storage solution, followed by the addition of
$12 \mu \mathrm{l}$ of riboFECT ${ }^{\mathrm{TM}} \mathrm{CP}$ reagent. After gently mixture and subsequent incubation at room temperature for $15 \mathrm{~min}$, the transfection complex was added into $2 \times 10^{6}$ DGCs cultured in neurobasal medium (final volume $2 \mathrm{ml}$ ) in the six-well plates with final concentration of siRNA at $150 \mathrm{nM}$, and incubated at $37^{\circ} \mathrm{C}$ in a humidified $5 \% \mathrm{CO}_{2}$ and $95 \%$ air atmosphere for $24 \mathrm{~h}$. The transfection efficiency of siRNA was accordingly measured.

\section{Western blot}

Proteins were extracted from neuronal cultures or hippocampus with a buffer containing $1 \% \mathrm{SDS}, 100 \mathrm{mmol} / \mathrm{l}$ Tris- $\mathrm{HCl}$, and $1 \mathrm{mmol} / \mathrm{PMSF}$. The protein concentration of each specimen was assessed by the BCA method to maintain the same loads. The protein extracts were heat-denatured at $95^{\circ} \mathrm{C}$ for $5 \mathrm{~min}$, electrophoretically separated on $10 \%$ SDS-PAGE, and transferred to PVDF membranes. The membranes were reacted with a 1:1000 dilution of primary antibodies in TBST buffer at $4{ }^{\circ} \mathrm{C}$ overnight, followed by reaction 
A

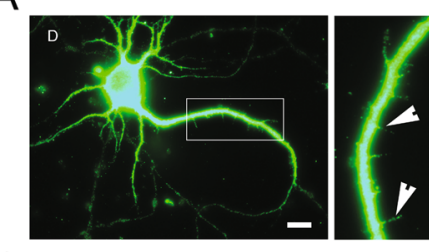

C

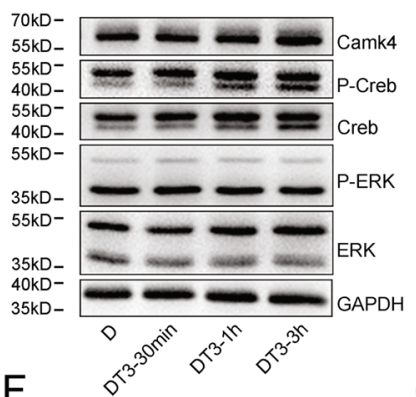

F

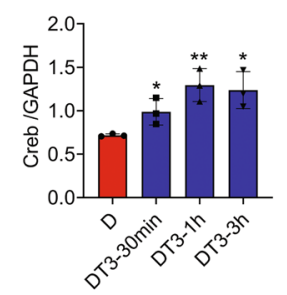

I

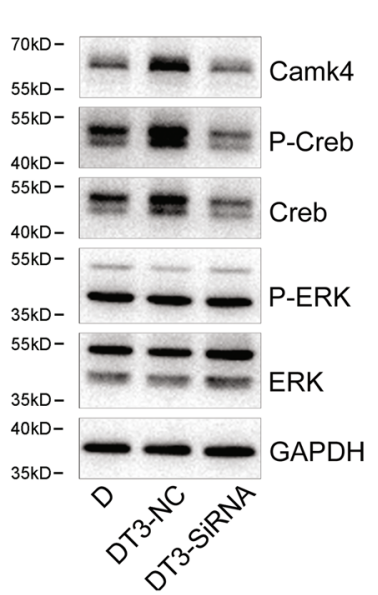

L

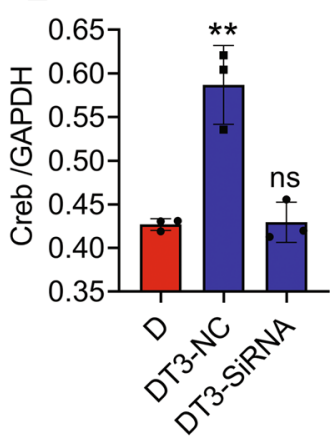

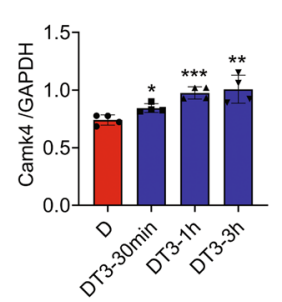

G

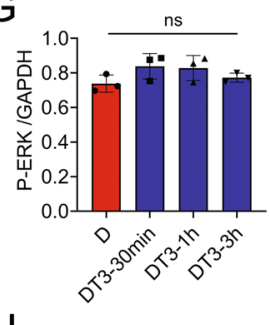

J

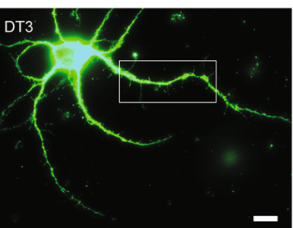

D

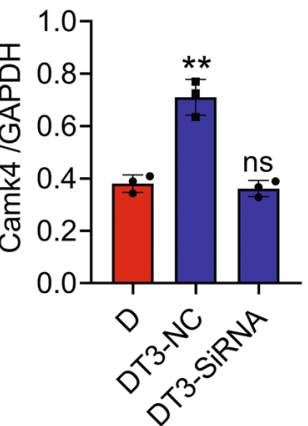

M

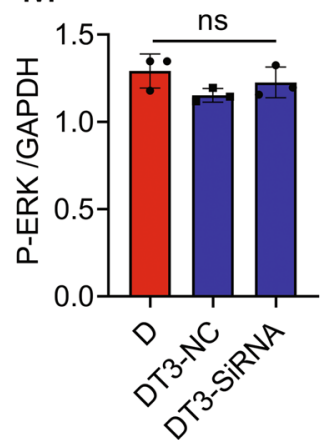

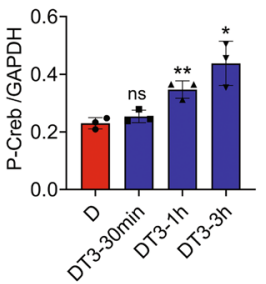

$\mathrm{H}$

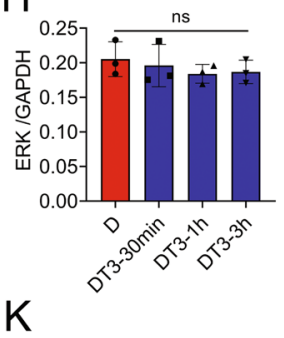

B

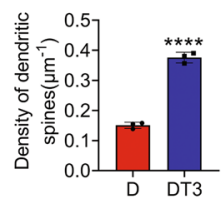

E

K

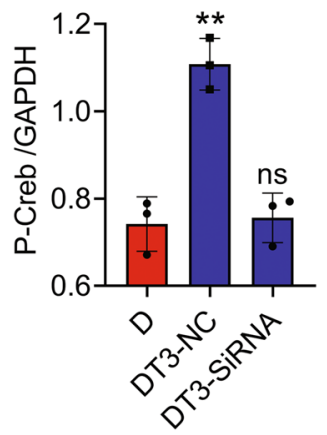

N

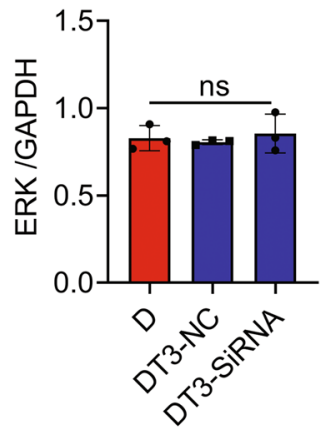

Fig. 7 T3 increased spine density of DGCs from CH fetal rat via activation of CREB. A DGCs from CH E18 fetus were treated with $5 \mathrm{nM}$ T3 for $24 \mathrm{~h}$, followed by culture for another 7 days. Spines were immunostained by MAP2 antibody. The rectangle indicates region magnified. Arrowheads indicate spines. B Statistical analysis of A. Spine density was analyzed in quadruplicates each 15 fields. Six pups of each group were used to isolate DGCs. C-H Western blot analysis of CaMKIV, p-CREB/CREB, and pERK/ERK following DGCs treatment with $5 \mathrm{nM}$ T3 for $30 \mathrm{~min}, 1 \mathrm{~h}$, and $3 \mathrm{~h}$, respectively. D-H are statistical analysis of C. I Western blot analysis of CaMKIV, p-CREB/CREB, and pERK/ERK following DGCs knockdown of CaMKIV for $24 \mathrm{~h}$, and then stimulated with $5 \mathrm{nM}$ T3 for $30 \mathrm{~min}$. J-N Statistical analysis of I. Experiments were performed in triplicates. Error bars represent the standard deviation $(P<0.05)$. Scale bars, $10 \mu \mathrm{m}$ in $\mathbf{A}$. 


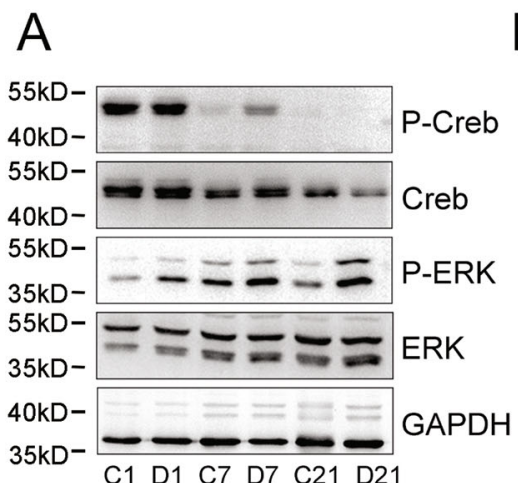

D

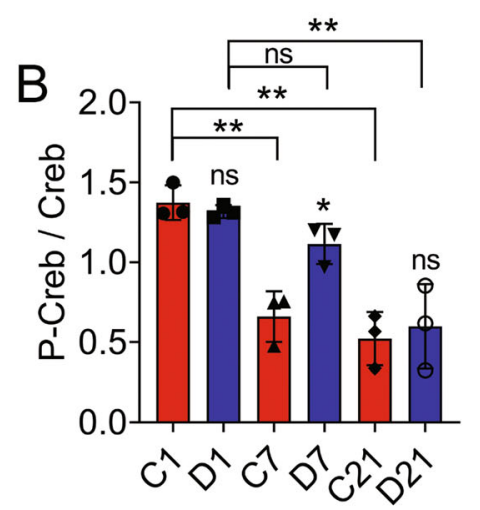

Days of age
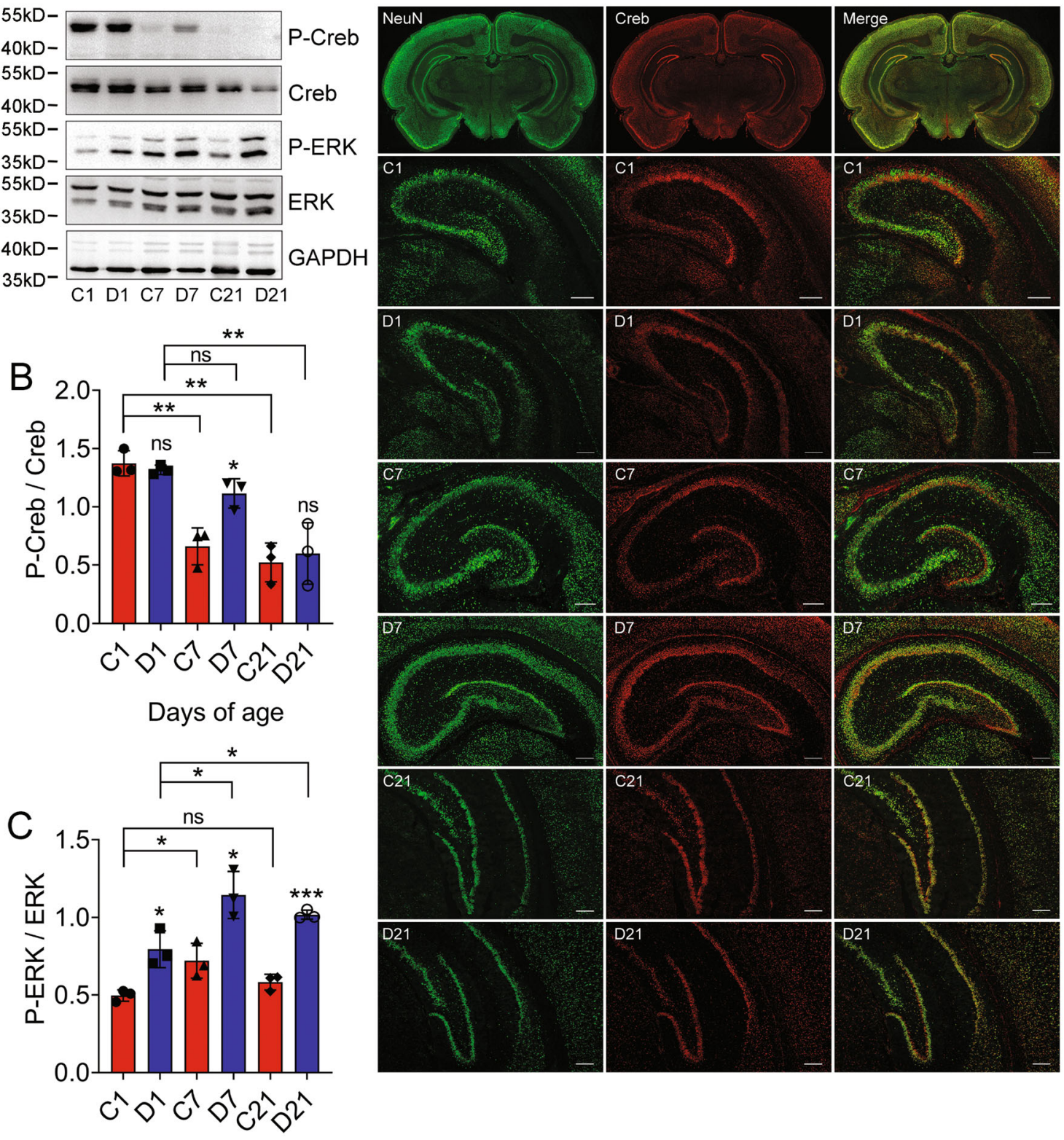

Days of age

Fig. 8 Expression analysis of CREB in the hippocampus of rat pups following CH. A Western blot analysis of p-CREB/CREB, $p E R K / E R K$ in the hippocampus of P1, P7, and P21 pups following CH. B, C Quantification data as shown in A. Experiments were performed in triplicates. Error bars represent the standard deviation $(P<0.05)$. D Immunostaining of CREB protein in the tissue section from hippocampus of P1, P7, and P21 rat pups following $\mathrm{CH}$. Scale bars, $200 \mu \mathrm{m}$.

with a secondary antibody conjugated with goat-anti-rabbit or donkey-antimouse HRP (Proteintech), diluted at 1:1000 at room temperature for $2 \mathrm{~h}$. After the membrane was washed, the HRP activity was detected using an ECL kit. Antibodies used for western blot were anti-CaMKIV antibody (1:1000; proteintech); anti-CREB antibody (1:1000; proteintech); anti-p-CREB antibody (1:1000; CST); anti-ERK antibody (1:1000; CST); anti-p-ERK antibody (1:1000; CST); and anti-GAPDH antibody (1:1000; CST).

\section{Transcriptome sequencing of pup hippocampus and \\ bioinformatics analysis}

Total RNA of hippocampus from P1, P7, and P21 pups with or without $\mathrm{CH}$, was extracted using the mirVana miRNA Isolation Kit (Ambion, Austin, TX), according to the manufacturer's instructions. They were then selected by RNA Purification Beads (Illumina, San Diego, CA), and undergone library construction and RNA-seq analysis. The library was constructed by using the Illumina TruSeq RNA sample Prep Kit v2 and sequenced by the Illumina HiSeq-2000 for 50 cycles. High-quality reads that passed the Illumina quality filters were kept for the sequence analysis.

Differentially expressed mRNA was designated in a criterion of greater or less than twofold change in comparison with control. Function of genes was annotated by Blastx against the NCBI database or the AGRIS database (https://agris-knowledgebase.org/) with $E$ value threshold of $10^{-5}$. GO classification was obtained by WEGO (http://wego.genomics.org.cn/) via GO id annotated by Perl and Rprogram. Kyoto Encyclopedia of Genes and Genomes (KEGG) pathways were assigned to the sequences using KEGG Automatic Annotation Server online. For all heatmaps, genes were clustered by Jensen-Shannon divergence. A reconstructed gene network was created using the IPA software on the basis of DEGs to investigate their regulatory pathways and cellular functions [72]. 
Quantitative real-time polymerase chain reaction (Q-PCR)

Total RNA was prepared with TRIzol (Gibco) from hippocampus or neuronal cultures upon demands. The first-strand CDNA was synthesized using the Omniscript reverse transcription kit (Qiagen) in a $20-\mu$ l reaction system containing $2 \mu \mathrm{g}$ total RNA, $0.2 \mathrm{U} / \mu \mathrm{l} \mathrm{M-MLV}$ reverse transcriptase, $0.5 \mathrm{mmol} / \mathrm{l}$ dNTP mix, and $1 \mu \mathrm{mol} / \mathrm{l}$ Oligo-dT primer. The CDNA was diluted 1:4 before use in Q-PCR assays. The sequence-specific primers were designed and synthesized by Generay (Shanghai, China): for CaMKIV, forward primer 5'TGG AGG CAG TTG CTT ACC TG-3' and reverse primer $5^{\prime}$-CCT CGG AGA ATC TCA GGT GC-3'; for CREB, forward primer 5'-GCA GTG ACT GAG GAG CTT GT-3' and reverse primer $5^{\prime}$-ACC TGG GCT AAT GTG GCA AT- $3^{\prime}$. The reactions were performed using one initial denaturation cycle at $94^{\circ} \mathrm{C}$ for $5 \mathrm{~min}$ followed by 45 cycles of $94^{\circ} \mathrm{C}$ for $30 \mathrm{~s}, 60^{\circ} \mathrm{C}$ for $30 \mathrm{~s}$, and $72^{\circ} \mathrm{C}$ for $30 \mathrm{~s}$. Fluorescence was recorded during each annealing step. At the end of each PCR run, the data were automatically analyzed by the system, and the amplification plots were obtained. The expression levels of the genes were normalized to an endogenous gapdh cDNA.

\section{Immunofluorescence}

The freshly dissected brain from pups at P1, P7, and P21 was fixed in 4\% paraformaldehyde in $0.1 \mathrm{M}$ phosphate buffer $(\mathrm{pH} 7.4)$ for $24 \mathrm{~h}$ at $4{ }^{\circ} \mathrm{C}$. They were subsequently dehydrated in 10,20 , and $30 \%$ sucrose dissolved in $0.1 \mathrm{M}$ phosphate buffer (pH 7.4). The brain was sectioned into $12-\mu \mathrm{m}$ slices in a cryostat. After washing in PBS, the slices were blocked in PBS containing $0.1 \%$ triton $\mathrm{X}-100,5 \%$ newborn goat serum, and $5 \%$ horse serum for $1 \mathrm{~h}$. The primary antibodies were diluted in PBS before added to the slices. After incubation at $4^{\circ} \mathrm{C}$ for $16 \mathrm{~h}$, the sections were washed with PBS, and the secondary antibodies were added and incubated at $4{ }^{\circ} \mathrm{C}$ for $16 \mathrm{~h}$. The slices were then washed in PBS and counterstained with $0.1 \mathrm{~g} / \mathrm{ml}$ Hoechst 33342 solution. Antibodies used in immunofluorescence were anti-NeuN antibody (1:1000; proteintech); anti-CaMKIV antibody (1:1000; proteintech); anti-CREB antibody (1:1000; proteintech); anti-MAP2 (1:500; abcam); donkey-anti-mouse Alexa 488; and and goat-anti-rabbit Cy3.

\section{Statistical analysis}

Statistical analysis used GraphPad Prism 8 software (San Diego, CA, USA). Normality and homoscedasticity of the data were performed using Levene's test. Independent sample $t$ test and one-way analysis of variance followed by Bonferroni's post hoc comparisons tests were utilized for comparisons for different groups. All data were presented as mean \pm standard deviation. Two-sided $P$ value $<0.05$ was considered statistically significant.

\section{DATA AVAILABILITY}

The datasets used and/or analyzed during the current study are available from the corresponding author on reasonable request.

\section{REFERENCES}

1. Peters C, van Trotsenburg ASP, Schoenmakers N. Diagnosis of endocrine disease: congenital hypothyroidism: update and perspectives. Eur J Endocrinol. 2018;179: R297-317.

2. Fisher DA. Second international conference on neonatal thyroid screening: progress report. J Pediatr. 1983;102:653-4.

3. Belfort MB, Pearce EN, Braverman LE, He X, Brown RS. Low iodine content in the diets of hospitalized preterm infants. J Clin Endocrinol Metab. 2012;97:E632-6.

4. Brown RS, Alter CA, Sadeghi-Nejad A. Severe unsuspected maternal hypothyroidism discovered after the diagnosis of thyrotropin receptor-blocking antibodyinduced congenital hypothyroidism in the neonate: failure to recognize and implications to the fetus. Horm Res Paediatr. 2015;83:132-5.

5. Bauer AJ, Wassner AJ. Thyroid hormone therapy in congenital hypothyroidism and pediatric hypothyroidism. Endocrine. 2019;66:51-62.

6. Onsesveren I, Barjaktarovic M, Chaker L, de Rijke YB, Jaddoe VWV, van Santen HM, et al. Childhood thyroid function reference ranges and determinants: a literature overview and a prospective cohort study. Thyroid. 2017;27:1360-9.

7. Salerno M, Capalbo D, Cerbone M, De, Luca F. Subclinical hypothyroidism in childhood - current knowledge and open issues. Nat Rev Endocrinol. 2016;12:734-46.

8. Cherella CE, Wassner AJ. Update on congenital hypothyroidism. Curr Opin Endocrinol Diabetes Obes. 2020;27:63-9.

9. Bernal J. Action of thyroid hormone in brain. J Endocrinol Investig. 2002;25: 268-88.
10. Bernal J. Thyroid hormone receptors in brain development and function. Nat Clin Pr Endocrinol Metab. 2007;3:249-59.

11. Dugbartey AT. Neurocognitive aspects of hypothyroidism. Arch Intern Med. 1998;158:1413-8.

12. Bernal J. Thyroid hormones and brain development. Vitam Horm. 2005;71: 95-122.

13. Manzano J, Cuadrado M, Morte B, Bernal J. Influence of thyroid hormone and thyroid hormone receptors in the generation of cerebellar gammaaminobutyric acid-ergic interneurons from precursor cells. Endocrinology. 2007; 148:5746-51.

14. Kapoor R, van Hogerlinden M, Wallis K, Ghosh H, Nordstrom K, Vennstrom B, et al. Unliganded thyroid hormone receptor alpha1 impairs adult hippocampal neurogenesis. FASEB J. 2010;24:4793-805.

15. Osterweil D, Syndulko K, Cohen SN, Pettler-Jennings PD, Hershman JM, Cummings $\mathrm{JL}$, et al. Cognitive function in non-demented older adults with hypothyroidism. J Am Geriatr Soc. 1992;40:325-35.

16. Desouza LA, Ladiwala U, Daniel SM, Agashe S, Vaidya RA, Vaidya VA. Thyroid hormone regulates hippocampal neurogenesis in the adult rat brain. Mol Cell Neurosci. 2005;29:414-26.

17. Kapoor R, Desouza LA, Nanavaty IN, Kernie SG, Vaidya VA. Thyroid hormone accelerates the differentiation of adult hippocampal progenitors. J Neuroendocrinol. 2012;24:1259-71.

18. Cheng SY, Leonard JL, Davis PJ. Molecular aspects of thyroid hormone actions. Endocr Rev. 2010;31:139-70.

19. Stone SS, Teixeira CM, Zaslavsky K, Wheeler AL, Martinez-Canabal A, Wang AH, et al. Functional convergence of developmentally and adult-generated granule cells in dentate gyrus circuits supporting hippocampus-dependent memory. Hippocampus. 2011;21:1348-62.

20. Kee N, Teixeira CM, Wang AH, Frankland PW. Preferential incorporation of adultgenerated granule cells into spatial memory networks in the dentate gyrus. Nat Neurosci. 2007;10:355-62

21. van Praag $H$, Schinder AF, Christie BR, Toni $N$, Palmer TD, Gage FH. Functional neurogenesis in the adult hippocampus. Nature. 2002;415:1030-4.

22. Ge S, Goh EL, Sailor KA, Kitabatake Y, Ming GL, Song H. GABA regulates synaptic integration of newly generated neurons in the adult brain. Nature. 2006;439:589-93.

23. Tashiro A, Sandler VM, Toni N, Zhao C, Gage FH. NMDA-receptor-mediated, cellspecific integration of new neurons in adult dentate gyrus. Nature. 2006:442:929-33.

24. McAvoy KM, Scobie KN, Berger S, Russo C, Guo N, Decharatanachart P, et al. Modulating neuronal competition dynamics in the dentate gyrus to rejuvenate aging memory circuits. Neuron. 2016;91:1356-73.

25. Rao S, Kirschen GW, Szczurkowska J, Di Antonio A, Wang J, Ge S, et al. Repositioning of somatic golgi apparatus is essential for the dendritic establishment of adult-born hippocampal neurons. J Neurosci. 2018;38:631-47.

26. Homma N, Zhou R, Naseer MI, Chaudhary AG, Al-Qahtani MH, Hirokawa N. KIF2A regulates the development of dentate granule cells and postnatal hippocampal wiring. Elife. 2018;7:e30935.

27. Yu F, Wang Y, Xu H, Dong J, Wei W, Wang Y, et al. Developmental iodine deficiency delays the maturation of newborn granule neurons associated with downregulation of p35 in postnatal rat hippocampus. Environ Toxicol. 2014;29:847-55.

28. Tai Y, Feng S, Ge R, Du W, Zhang X, He Z, et al. TRPC6 channels promote dendritic growth via the CaMKIV-CREB pathway. J Cell Sci. 2008;121:2301-7.

29. Redmond L, Kashani AH, Ghosh A. Calcium regulation of dendritic growth via CaM kinase IV and CREB-mediated transcription. Neuron. 2002;34:999-1010.

30. Nagendran T, Hardy LR. Calcium/calmodulin-dependent protein kinase IV mediates distinct features of basal and activity-dependent dendrite complexity. Neuroscience. 2011;199:548-62.

31. Kasahara J, Fukunaga K, Miyamoto E. Activation of calcium/calmodulin-dependent protein kinase IV in long term potentiation in the rat hippocampal CA1 region. J Biol Chem. 2001;276:24044-50.

32. Liu YY, Brent GA. A complex deoxyribonucleic acid response element in the rat $\mathrm{Ca}$ $(2+)$ /calmodulin-dependent protein kinase IV gene $5^{\prime}$-flanking region mediates thyroid hormone induction and chicken ovalbumin upstream promoter transcription factor 1 repression. Mol Endocrinol. 2002;16:2439-51.

33. Morte B, Diez D, Auso E, Belinchon MM, Gil-lbanez P, Grijota-Martinez C, et al. Thyroid hormone regulation of gene expression in the developing rat fetal cerebral cortex: prominent role of the $\mathrm{Ca} 2+/$ calmodulin-dependent protein kinase IV pathway. Endocrinology. 2010;151:810-20.

34. Calvo R, Obregon MJ, Ruiz de Ona C, Escobar del Rey F, Morreale, de Escobar G. Congenital hypothyroidism, as studied in rats. Crucial role of maternal thyroxine but not of 3,5,3'-triiodothyronine in the protection of the fetal brain. J Clin Investig. 1990;86:889-99. 
35. Song $H$, Zheng $Y$, Cai F, Ma Y, Yang J, Wu Y. c-Fos downregulation positively regulates EphA5 expression in a congenital hypothyroidism rat model. J Mol Histol. 2018;49:147-55.

36. Wu Y, Song H, Sun B, Xu M, Shi J. DNA methylation of the EphA5 promoter is associated with rat congenital hypothyroidism. J Mo. Neurosci. 2015;57: 203-10.

37. Dumas TC, Powers EC, Tarapore PE, Sapolsky RM. Overexpression of calbindin D (28k) in dentate gyrus granule cells alters mossy fiber presynaptic function and impairs hippocampal-dependent memory. Hippocampus. 2004;14:701-9.

38. Anderson GW, Schoonover CM, Jones SA. Control of thyroid hormone action in the developing rat brain. Thyroid. 2003;13:1039-56.

39. Nakagawa S, Kim JE, Lee R, Malberg JE, Chen J, Steffen C, et al. Regulation of neurogenesis in adult mouse hippocampus by CAMP and the cAMP response element-binding protein. J Neurosci. 2002;22:3673-82.

40. Wu GY, Deisseroth K, Tsien RW. Activity-dependent CREB phosphorylation: convergence of a fast, sensitive calmodulin kinase pathway and a slow, less sensitive mitogen-activated protein kinase pathway. Proc Natl Acad Sci USA. 2001;98:2808-13.

41. Kilberg MJ, Rasooly IR, LaFranchi SH, Bauer AJ, Hawkes CP. Newborn screening in the US may miss mild persistent hypothyroidism. J Pediatr. 2018;192:204-8.

42. Sugisawa C, Takamizawa T, Abe K, Hasegawa T, Shiga K, Sugawara H, et al. Genetics of congenital isolated TSH deficiency: mutation screening of the known causative genes and a literature review. J Clin Endocrinol Metab. 2019:104:6229-37.

43. Casey BM, Thom EA, Peaceman AM, Varner MW, Sorokin Y, Hirtz DG, et al. Treatment of subclinical hypothyroidism or hypothyroxinemia in pregnancy. $\mathrm{N}$ Engl J Med. 2017;376:815-25.

44. Min H, Dong J, Wang $Y$, Wang $Y$, Teng $W, X i$ Q, et al. Maternal hypothyroxinemiainduced neurodevelopmental impairments in the progeny. Mol Neurobiol. 2016;53:1613-24.

45. Yang $X, Y u$ Y, Zhang C, Zhang Y, Chen Z, Dubois L, et al. The association between isolated maternal hypothyroxinemia in early pregnancy and preterm birth. Thyroid. 2020;30:1724-31.

46. Liu YY, Brent GA. Thyroid hormone and the brain: mechanisms of action in development and role in protection and promotion of recovery after brain injury. Pharm Ther. 2018;186:176-85.

47. Boelaert K, Franklyn JA. Thyroid hormone in health and disease. J Endocrinol. 2005; 187:1-15.

48. Chen $Y$, Xue F. The impact of gestational hypothyroxinemia on the cognitive and motor development of offspring. J Matern Fetal Neonatal Med. 2020;33:1940-5.

49. Forster E, Zhao S, Frotscher M. Laminating the hippocampus. Nat Rev Neurosci. 2006;7:259-67.

50. Frotscher $M$, Jonas $P$, Sloviter RS. Synapses formed by normal and abnormal hippocampal mossy fibers. Cell Tissue Res. 2006;326:361-7.

51. Dashtipour K, Yan XX, Dinh TT, Okazaki MM, Nadler JV, Ribak CE. Quantitative and morphological analysis of dentate granule cells with recurrent basal dendrites from normal and epileptic rats. Hippocampus. 2002;12:235-44.

52. Wang XX, Li JT, Xie XM, Gu Y, Si TM, Schmidt MV, et al. Nectin-3 modulates the structural plasticity of dentate granule cells and long-term memory. Transl Psychiatry. 2017;7:e1228.

53. Patel LS, Wenzel HJ, Schwartzkroin PA. Physiological and morphological characterization of dentate granule cells in the p35 knock-out mouse hippocampus: evidence for an epileptic circuit. J Neurosci. 2004;24:9005-14.

54. Nadler JV, Perry BW, Cotman CW. Intraventricular kainic acid preferentially destroys hippocampal pyramidal cells. Nature. 1978;271:676-7.

55. Conrad CD, Roy EJ. Selective loss of hippocampal granule cells following adrenalectomy: implications for spatial memory. J Neurosci. 1993;13:2582-90.

56. Sloviter RS, Valiquette G, Abrams GM, Ronk EC, Sollas AL, Paul LA, et al. Selective loss of hippocampal granule cells in the mature rat brain after adrenalectomy. Science. 1989;243:535-8.

57. Swulius MT, Waxham MN. $\mathrm{Ca}(2+) /$ calmodulin-dependent protein kinases. Cell Mol Life Sci. 2008;65:2637-57.

58. Bayer KU, Schulman H. CaM kinase: still inspiring at 40. Neuron. 2019;103:380-94.

59. Krebs J. Implications of the thyroid hormone on neuronal development with special emphasis on the calmodulin-kinase IV pathway. Biochim Biophys Acta Mol Cell Res. 2017;1864:877-82.

60. Bito H, Deisseroth K, Tsien RW. CREB phosphorylation and dephosphorylation: a $\mathrm{Ca}(2+)$ - and stimulus duration-dependent switch for hippocampal gene expression. Cell 1996;87:1203-14.

61. Ohmstede CA, Jensen KF, Sahyoun NE. Ca2+/calmodulin-dependent protein kinase enriched in cerebellar granule cells. Identification of a novel neuronal calmodulin-dependent protein kinase. J Biol Chem. 1989;264:5866-75.

62. Lonze BE, Ginty DD. Function and regulation of CREB family transcription factors in the nervous system. Neuron. 2002;35:605-23.
63. Laviv T, Scholl B, Parra-Bueno $P$, Foote B, Zhang C, Yan L, et al. In vivo imaging of the coupling between neuronal and CREB activity in the mouse brain. Neuron. 2020;105:799-812. e795.

64. Ao $\mathrm{H}$, Ko SW, Zhuo M. CREB activity maintains the survival of cingulate cortical pyramidal neurons in the adult mouse brain. Mol Pain. 2006;2:15.

65. Ortega-Martinez S. A new perspective on the role of the CREB family of transcription factors in memory consolidation via adult hippocampal neurogenesis. Front Mol Neurosci. 2015;8:46.

66. Gonzalez-Gutierrez A, Lazo OM, Bronfman FC. The Rab5-Rab11 endosomal pathway is required for BDNF-induced CREB transcriptional regulation in hippocampal neurons. J Neurosci. 2020;40:8042-54.

67. Miyashita T, Kikuchi E, Horiuchi J, Saitoe M. Long-term memory engram cells are established by c-Fos/CREB transcriptional cycling. Cell Rep. 2018;25:2716-28. e2713.

68. Lisman J, Cooper K, Sehgal M, Silva AJ. Memory formation depends on both synapse-specific modifications of synaptic strength and cell-specific increases in excitability. Nat Neurosci. 2018;21:309-14.

69. Kandezi N, Mohammadi M, Ghaffari M, Gholami M, Motaghinejad M, Safari S. Novel insight to neuroprotective potential of curcumin: a mechanistic review of possible involvement of mitochondrial biogenesis and $\mathrm{PI3/Akt/GSK3}$ or $\mathrm{PI} / \mathrm{Akt} /$ CREB/BDNF signaling pathways. Int J Mol Cell Med. 2020;9:1-32.

70. Impey S, Fong AL, Wang Y, Cardinaux JR, Fass DM, Obrietan K, et al. Phosphorylation of CBP mediates transcriptional activation by neural activity and CaM kinase IV. Neuron. 2002;34:235-44.

71. Zhou Z, Tanaka KF, Matsunaga S, Iseki M, Watanabe M, Matsuki N, et al. Photoactivated adenylyl cyclase (PAC) reveals novel mechanisms underlying CAMPdependent axonal morphogenesis. Sci Rep. 2016;5:19679.

72. Kramer A, Green J, Pollard J Jr., Tugendreich S. Causal analysis approaches in ingenuity pathway analysis. Bioinformatics. 2014;30:523-30.

\section{ACKNOWLEDGEMENTS}

We thank Prof. Mei Liu for providing platform of Morris water maze tests.

\section{AUTHOR CONTRIBUTIONS}

$\mathrm{Y}$. $\mathrm{Wu}$ designed this work and wrote the paper. Q.T. and S.C. performed the experiments. H.W., H.S., Y. Wang, and J.S. analyzed the data. Y. Wang, J.S., and Y. Wu joined discussions. All authors have approved the present version of the manuscript and have agreed to be accountable for all aspects of the work, regarding questions related to the accuracy or integrity of any part of the work.

\section{FUNDING}

This study was supported by National Natural Science Youth Fund (81700696), Jiangsu Provincial Medical Youth Talent (QNRC2016684), 333 Scientific Research Project of Jiangsu Province (BRA2020396), Science and Technology Program of Nantong (MS22019002 and MS22020002), and Postgraduate Research and Practice Innovation Program of Jiangsu Province (SJCX19_0870).

\section{COMPETING INTERESTS}

The authors declare no competing interests.

\section{ETHICS APPROVAL AND CONSENT TO PARTICIPATE}

All animal experiments were approved by the Animal Care and Use Committee of Nantong University and the Jiangsu Province Animal Care Ethics Committee.

\section{ADDITIONAL INFORMATION}

Supplementary information The online version contains supplementary material available at https://doi.org/10.1038/s41420-021-00530-z.

Correspondence and requests for materials should be addressed to J.S. or Y.W.

Reprints and permission information is available at http://www.nature.com/ reprints

Publisher's note Springer Nature remains neutral with regard to jurisdictional claims in published maps and institutional affiliations. 
Open Access This article is licensed under a Creative Commons Ac Attribution 4.0 International License, which permits use, sharing,
adaptation, distribution and reproduction in any medium or format, as long as you give appropriate credit to the original author(s) and the source, provide a link to the Creative Commons license, and indicate if changes were made. The images or other third party material in this article are included in the article's Creative Commons license, unless indicated otherwise in a credit line to the material. If material is not included in the article's Creative Commons license and your intended use is not permitted by statutory regulation or exceeds the permitted use, you will need to obtain permission directly from the copyright holder. To view a copy of this license, visit http://creativecommons. org/licenses/by/4.0/.

(c) The Author(s) 2021 